\title{
Dietary predictors of plasma total homocysteine in the Hordaland Homocysteine Study
}

\author{
Svetlana V. Konstantinova ${ }^{1}$, Stein Emil Vollset ${ }^{1}$, Paula Berstad ${ }^{2}$, Per Magne Ueland ${ }^{3}$, \\ Christian A. Drevon ${ }^{2}$, Helga Refsum ${ }^{2,4}$ and Grethe S. Tell ${ }^{1}$ \\ ${ }^{1}$ Section of Epidemiology and Medical Statistics, Department of Public Health and Primary Health Care, University of Bergen, \\ Kalfarveien, 31, 5018 Bergen, Norway \\ ${ }^{2}$ Department of Nutrition, Institute of Basic Medical Sciences, University of Oslo, P.O. Box 1046 Blindern, 0316 Oslo, Norway \\ ${ }^{3}$ Section of Pharmacology, Institute of Medicine, University of Bergen, Armauer Hansens hus, 5021 Bergen, Norway \\ ${ }^{4}$ Department of Physiology, Anatomy \& Genetics, Oxford Centre for Gene Function, University of Oxford, Parks Rd., \\ Oxford, OX1 3PT, UK
}

(Received 11 September 2006 - Revised 8 December 2006 - Accepted 15 January 2007)

\begin{abstract}
Established dietary predictors of plasma total homocysteine (tHcy) include folate, riboflavin, and vitamins $\mathrm{B}_{6}$ and $\mathrm{B}_{12}$, while information is scarce regarding other dietary components. The aim of this study was to examine the relation between a variety of food groups, food items and nutrients, and plasma tHcy in a large population-based study. The study population included 5812 men and women aged 47-49 and 71-74 years who completed a 169-item FFQ. tHcy was examined across quartiles of dietary components by multiple linear regression analyses adjusting for age, sex, energy intake, various risk factors for elevated tHcy, as well as for dietary and plasma B-vitamins. Among 4578 non-users of vitamin supplements, intake of vegetables, fruits, cereals, eggs, fish and milk, as well as chicken and non-processed meats were inversely associated with tHcy level. The estimated mean difference in tHcy per increasing quartile of intake ranged from $-0.11(95 \% \mathrm{CI}-0.21,-0.01) \mu \mathrm{mol} / \mathrm{l}$ for milk to -0.32 $(95 \%$ CI $-0.42,-0.22) \mu \mathrm{mol} / 1$ for vegetables. Positive associations were found for sweets and cakes. Whole-grain bread was significantly inversely related to tHcy only after additional adjustment for dietary and plasma B-vitamins. The nutrients folate, vitamin $\mathrm{B}_{6}$, $\mathrm{B}_{12}$, and riboflavin were inversely related to tHcy. Complex carbohydrates were inversely, and fat positively associated with tHcy, also after adjustment for dietary and plasma B-vitamins. In conclusion, food items rich in B-vitamins and with a low content of fat and sugar were related to lower tHcy levels. Eggs, chicken, non-processed meat, fish and milk were inversely associated with tHcy.
\end{abstract}

Homocysteine: Diet: Food groups: Food items: Nutrients

Homocysteine is an intermediate amino acid in the metabolism of the essential amino acid methionine (Castro et al. 2006). Elevated plasma total homocysteine (tHcy) concentration has been related to several adverse conditions and diseases, including adverse pregnancy outcomes (Scholl \& Johnson, 2000; Daly et al. 2005), cognitive dysfunction among elderly (Morris, 2003) and recently osteoporosis (Gjesdal et al. 2006). Plasma tHcy also predicts CVD risk in prospective studies (de Bree et al. 2002; Wald et al. 2002), but intervention trials do not demonstrate risk reduction by tHcy-lowering therapy with high doses of B-vitamins in patients with established CVD (Clarke, 2005; Bonaa et al. 2006; Loscalzo, 2006).

Elevated tHcy is observed under a variety of conditions, e.g. deficiency of B-vitamins (Verhoef \& de Groot, 2005; Castro et al. 2006), smoking (Nygard et al. 1998; Ortega et al. 2004), high coffee consumption (Ranheim \& Halvorsen, 2005; Verhoef \& de Groot, 2005) and impaired renal function (Perna et al. 2004; Castro et al. 2006). The concentration of tHcy in plasma can be lowered by enhanced remethylation of homocysteine into methionine or via degradation through the transsulphuration pathway. Folate or betaine donate a methyl group, while vitamin $\mathrm{B}_{12}$, vitamin $\mathrm{B}_{6}$ and riboflavin act as cofactors for enzymes involved in homocysteine metabolism (Finkelstein, 1990; Ueland et al. 2005; Castro et al. 2006).

Several studies report an association between intake of different nutrients and plasma tHcy concentration (Vollset et al. 2001; Verhoef \& de Groot, 2005; Castro et al. 2006). Many studies, particularly the two largest studies - the Framingham Offspring study ( $n$ 1960) and the Dutch study ( $n$ 2435) - have found inverse associations between plasma tHcy and intake of folate, vitamin $\mathrm{B}_{12}$, vitamin $\mathrm{B}_{6}$ and riboflavin (de Bree et al. 2001; Jacques et al. 2001). Also, mandatory food fortification with folic acid has increased the level of plasma folate and decreased tHcy concentration in the general US population (Jacques et al. 1999; Pfeiffer et al. 2005; Ganji \& Kafai, 2006).

There are contradictory reports on the relation between protein and methionine to plasma tHcy concentration (Verhoef \& de Groot, 2005). A few studies that examined the associations

Abbreviations: NNR, Nordic Nutritional Recommendations; tHcy, total homocysteine.

* Corresponding author: Dr Svetlana V. Konstantinova, fax +47 55586 130, email Svetlana.Konstantinova@isf.uib.no 
with total fat, cholesterol, saturated fat, mono- and polyunsaturated fat (Shimakawa et al. 1997) and n-3 fatty acids (Brude et al. 1999) did not show statistically significant associations with tHcy concentration. Although less studied, dietary choline and betaine have been inversely related to plasma tHcy (Verhoef \& de Groot, 2005; Cho et al. 2006).

The alteration in plasma homocysteine concentration may vary substantially depending on the food source (Vollset et al. 2001). Previous studies show that tHcy concentration is inversely related to the intake of food groups such as bread (Vollset et al. 2001), cereals (Shimakawa et al. 1997; Ganji \& Kafai, 2004), fruits (Tucker et al. 1996; Vollset et al. 2001), vegetables (Tucker et al. 1996; Brude et al. 1999; Vollset et al. 2001), and to individual food items including cruciferous vegetables (Tucker et al. 1996; Ganji \& Kafai, 2004), peppers (Ganji \& Kafai, 2004), citrus fruits and juices (Tucker et al. 1996; Vollset et al. 2001), cold breakfast cereals (Tucker et al. 1996; Shimakawa et al. 1997; Ganji \& Kafai, 2004), milk (Shimakawa et al. 1997; Ganji \& Kafai, 2004), yoghurt (Ganji \& Kafai, 2004) and liver (Vollset et al. 2001). Positive associations have been found with caffeinecontaining drinks such as coffee (Jacques et al. 2001; Verhoef $\&$ de Groot, 2005), Coca Cola (Jacques et al. 2001) and tea (Jacques et al. 2001; Verhoef \& de Groot, 2005), while findings on alcohol are conflicting (Jacques et al. 2001; Vollset et al. 2001). To understand the associations between plasma tHcy concentration and foods with high and low B-vitamin content, we included major food groups and individual food items in the present study. Moreover, we examined to what extent dietary intake of folate, vitamin $\mathrm{B}_{12}$, vitamin $\mathrm{B}_{6}$, riboflavin and other nutrients may alter the plasma concentration of tHcy. We also investigated nutrients other than B-vitamins because our comprehensive dietary data allowed us to quantitatively assess the confounding effect of B-vitamins. Thus, the objective of the present paper was to assess the relationship between nutrients and food intake on plasma concentration of tHcy in middle-aged and older men and women in a large population-based study.

\section{Subjects and methods}

\section{Subjects}

The second round of the Hordaland Homocysteine Study was conducted as part of the Hordaland Health Study (HUSK), from 1997 to 1999 as a collaboration between the National Health Screening Service (now the Norwegian Institute of Public Health), The University of Bergen and local health services. Of the total sample of 9187 men and women born 1925-7 and 1950-1 who were invited to participate in the Hordaland Health Study, 7074 (77\%) agreed to participate. The participants underwent a brief health examination and donated a non-fasting blood sample. Information on diet and lifestyle was collected via self-administered questionnaires. In total 6140 subjects $(87 \%)$ completed a FFQ and 6118 of these also had plasma tHcy values measured. The study protocol was approved by the Regional Committee for Medical Research Ethics and the Norwegian Data Inspectorate. All subjects gave their written consent to participate in the study.

We excluded participants with reported energy intake below the 2.5 percentile $(2124 \mathrm{~kJ}$ for women $71-74$ years and
$3899 \mathrm{~kJ}$ for women $47-49$ years; $3856 \mathrm{~kJ}$ for men $71-74$ years and $5572 \mathrm{~kJ}$ for men $47-49$ years) and above the 97.5 percentile $(11098 \mathrm{~kJ}$ for women $71-74$ years and $12970 \mathrm{~kJ}$ for women 47-49 years; $14023 \mathrm{~kJ}$ for men 71-74 years and $17590 \mathrm{~kJ}$ for men 47-49 years). Thus, 141 men and 187 women were excluded from further analyses, yielding a final number of 5812 participants. Participants with reported seasonal or regular intake of at least one dose of multi- or/and individual vitamin supplement (excluding fish oil and $n-3$ fatty acids) per day were assigned to the vitamin supplement user group (n 1234).

\section{FFQ}

In the present study we used a 169 -item FFQ, a slightly modified version of a FFQ previously described in detail (Andersen et al. 1999). This FFQ aimed to capture the habitual diet during the past year. The FFQ includes frequency alternatives (from once a month to several times per day), the number of units eaten and portion sizes (e.g. slices, glasses, cups, pieces, spoons).

The information from the FFQ is presented as individual food items, food groups (consisting of individual food items) and nutrients. Individual food items correspond to the items listed on the questionnaire, whereas 'food groups' include related food items (e.g. the food group 'bread' contains 'bread with low, medium and high quantity of fibre').

In addition to individual food items, the FFQ also includes nine questions about the most commonly used brands of single- and multi-vitamin supplements on the market. Subjects using at least one dose of vitamin supplement per day seasonally or regularly during the past year were classified as vitamin supplement users.

Daily nutrient intakes were computed from a database and software system developed at the Department of Nutrition, University of Oslo (KBS, version 3.2). The nutrient database is mainly based on the official Norwegian food composition table with an update on folate content from 2001 (Rimestad et al. 2001). B-vitamin intake in supplements is calculated from information on the contents of vitamin supplements for sale during 1997-9.

\section{Health examination and analytic procedures}

A brief examination included measurements of height and weight and drawing of non-fasting blood samples. Tubes with plasma containing EDTA were stored at $-80^{\circ} \mathrm{C}$. Plasma tHcy was determined by automated HPLC with fluorescence detection. Intra-assay CV was $3 \%$ (Fiskerstrand et al. 1993). The concentration of plasma folate was measured by a Lactobacillus casei microbiological assay (Molloy \& Scott, 1997) and plasma vitamin $B_{12}$ concentration by a Lactobacillus leichmannii microbiological assay (Kelleher \& Broin, 1991). The concentration of serum creatinine was measured with standard alkaline picrate colorimetric assay.

\section{Statistical analysis}

Differences between non-users and users of vitamin supplements were assessed by linear regression with adjustment for age and sex for continuous variables and logistic 
regression with adjustment for age and/or sex for categorical variables. Spearman's partial correlation coefficients were used to estimate associations between dietary and plasma B-vitamins, other nutrients and food groups. Associations between predictor variables (food groups and nutrients) and plasma tHcy concentration were analysed separately for nonusers and users of vitamin supplements by multiple regression adjusted for age, sex and energy intake. Quartiles of predictor variables were defined separately for vitamin supplement users and non-users. Results were combined for the two age groups and for men and women, because the observed trends were similar in all the four age-sex groups. The potential effect modification (interaction) of vitamin supplement use on associations between diet and plasma tHcy was assessed by linear regression analysis with product terms of supplement use (0 or 1$)$ and each dietary predictor (with both main effects in the model) adjusted for age, sex and energy intake. We found an interaction effect of vitamin user group on the associations with several food groups and nutrients. Thus, due to the present results and the fact that B-vitamin supplementation may substantially reduce plasma tHcy concentration and therefore mask the effects of dietary components, we restricted the study sample to non-users of vitamin supplements in further in-depth analyses.

Multiple linear regression analysis was used to assess the simultaneous relations between various predictors of plasma tHcy concentration. The predictor variables (food groups, food items and nutrients) were categorized in quartiles, excluding refined bread. Due to low consumption of refined bread ( $29 \%$ of participants), three non-equal categories were used: 'non-user', '0-25 g/d', ' $>25 \mathrm{~g} / \mathrm{d}$ ', separating users in two groups of similar sizes. Thus, the regression coefficients estimated the mean differences in plasma tHcy concentration between quartiles of the predictor variables. Several models were used: Model I was adjusted for age, sex and energy intake (Table 2); Model II included additional adjustment for smoking and coffee consumption, as well as for BMI and serum creatinine (Tables 4 and 5); and Model III was further adjusted for dietary B-vitamin intake (folate, vitamin $\mathrm{B}_{12}$, vitamin $\mathrm{B}_{6}$, riboflavin) and plasma concentrations of folate and vitamin $\mathrm{B}_{12}$ (Tables 4 and 5). Findings with adjustment for dietary but not plasma B-vitamins are presented in the text only. We used additional adjustment for plasma folate and vitamin $B_{12}$ because their associations with tHcy were stronger than between tHcy and dietary B-vitamins. In addition, concentrations of folate and vitamin $B_{12}$ in plasma were relatively weakly correlated with the intake of dietary B-vitamins (Table 3). The continuous predictor variables were categorized in quartiles to use the mean difference of homocysteine per increasing quartile as the main effect measure. All statistical analyses were performed using SAS for Windows version 9.1 (SAS Institute Inc., Cary, NC, USA).

\section{Results}

\section{Characteristics of study population}

Descriptive statistics of the study population and its dietary habits are shown in Table 1 . There was a higher proportion of women in the group of vitamin supplement users compared to non-users. In age- and sex-adjusted analyses, supplement users had a lower proportion of smokers, lower BMI and coffee consumption, and higher intakes of cereals, fruits, vegetables and fish compared to non-users. The former group also had lower concentrations of tHcy, whereas folate and vitamin $\mathrm{B}_{12}$ were higher.

A lower intake than recommended in the Nordic Nutritional Recommendations (NNR) of folate $(300 \mu \mathrm{g} / \mathrm{d})$ was observed among $39 \%$ of vitamin supplement users and among $59 \%$ of non-users; the corresponding proportions were $1 \%$ and $3 \%$ for vitamin $B_{12}$ (NNR: $2 \mu \mathrm{g} / \mathrm{d}$ ), respectively. Less than the recommended intake of vitamin $B_{6}(\mathrm{NNR}: 1.2 \mathrm{mg} / \mathrm{d}$ for women, $1.6 \mathrm{mg} / \mathrm{d}$ for men) was registered among $49 \%$ of women and $57 \%$ of men in the group of non-users of vitamin supplements and $31 \%$ and $38 \%$ in the group of users, respectively. Less than the recommended intake of riboflavin (NNR: $1.3 \mathrm{mg} / \mathrm{d}$ for women, $1.7 \mathrm{mg} / \mathrm{d}$ for men) was observed among $44 \%$ of the women and $48 \%$ of the men among non-users of vitamin supplements and $22 \%$ of the women and $28 \%$ of the men among supplement users.

Relation between dietary intake and total homocysteine among non-users and users of vitamin supplements

Table 2 shows mean differences in plasma tHcy concentration between quartiles of food group and nutrient intake among non-users and users of vitamin supplements, after adjustment for age, sex and energy intake. While the associations between food groups and nutrients with plasma tHcy were mostly similar between users and non-users of vitamin supplements, there were some marked exceptions. Intake of vegetables was significantly inversely associated with plasma tHcy among nonusers only, whereas meat intake was significant only among vitamin supplement users. For these food groups, as well as for eggs, fats, sweets, protein and the nutrient fat, there was a significant effect modification of vitamin supplement use on the associations with tHcy. There was a similar effect for energy intake, which was significantly inversely related to tHcy among non-users only.

\section{Correlations between dietary and plasma B-vitamins, food groups and other macro- and micro-nutrients}

Dietary folate intake was significantly positively correlated with the intake of vegetables, fruits and fibre, as well as with most other vitamins, except vitamin D (Table 3). Dietary vitamin $\mathrm{B}_{12}$ was most strongly associated with fish intake, and also with meat, milk, protein, cholesterol and vitamin $\mathrm{B}_{6}$ and riboflavin. Dietary folate, $\mathrm{B}_{6}$ and riboflavin were positively associated with the intake of complex carbohydrates, and inversely associated with the intake of simple carbohydrates. Fat intake was inversely related to plasma folate and the dietary $\mathrm{B}$-vitamins, except dietary $\mathrm{B}_{12}$.

Plasma concentration of folate was moderately correlated with intake of fruits and vegetables, as well as with dietary folate and vitamin $\mathrm{B}_{6}$. Plasma vitamin $\mathrm{B}_{12}$ was significantly associated with fish and milk intake, as well as with dietary vitamin $\mathrm{B}_{12}$ and riboflavin. Plasma tHcy had stronger correlations with plasma folate and vitamin $\mathrm{B}_{12}$ than with dietary intake of folate, vitamin $\mathrm{B}_{12}$, vitamin $\mathrm{B}_{6}$ and riboflavin. 
Table 1. Characteristics of the study population and its diet, stratified by vitamin supplement use in the Hordaland Homocysteine Study

\begin{tabular}{|c|c|c|c|c|c|}
\hline \multirow{2}{*}{ Sex } & \multicolumn{2}{|c|}{$\begin{array}{l}\text { Non-users of vitamin } \\
\text { supplements }(n 4578)\end{array}$} & \multicolumn{2}{|c|}{$\begin{array}{l}\text { Users of vitamin } \\
\text { supplements }(n 1234)\end{array}$} & \multirow{2}{*}{$<0.0001$} \\
\hline & & & & & \\
\hline Men $(n)$ & & 2103 & & 447 & \\
\hline Women $(n)$ & & 2475 & & 787 & \\
\hline$\%$ (male/female) & & $46 / 54$ & & $36 / 64$ & \\
\hline Age group $(n)$ & & & & & 0.90 \\
\hline $47-49$ years & & 2324 & & 631 & \\
\hline $71-74$ years & & 2254 & & 603 & \\
\hline Smoking status (\%) & & & & & $0.004 \dagger$ \\
\hline Current smokers & & 24.6 & & $20 \cdot 8$ & \\
\hline Former smokers & & $38 \cdot 8$ & & $42 \cdot 4$ & \\
\hline \multirow[t]{2}{*}{ Never smokers } & & $34 \cdot 8$ & & 34.9 & \\
\hline & Mean & SD & Mean & SD & $P^{\star}$ \\
\hline BMI $\left(\mathrm{kg} / \mathrm{m}^{2}\right)$ & $25 \cdot 8$ & $3 \cdot 8$ & $25 \cdot 3$ & $3 \cdot 8$ & $<0.0001$ \\
\hline Coffee consumption $(\mathrm{ml} / \mathrm{d})$ & 447 & 292 & 400 & 283 & $<0.0001$ \\
\hline \multicolumn{6}{|l|}{ Food group $(g / d)$} \\
\hline Bread & 177 & 75 & 171 & 71 & 0.81 \\
\hline Cereals & 33 & 30 & 38 & 33 & $<0.0001$ \\
\hline Cakes, pies, cookies & 26 & 26 & 25 & 23 & 0.48 \\
\hline Fruit & 234 & 167 & 267 & 174 & $<0.0001$ \\
\hline Vegetables & 191 & 143 & 216 & 136 & $<0.0001$ \\
\hline Potatoes & 121 & 71 & 115 & 67 & 0.81 \\
\hline Meat & 98 & 59 & 97 & 53 & 0.25 \\
\hline Fish and seafood & 83 & 54 & 88 & 51 & $<0.0001$ \\
\hline Eggs & 16 & 11 & 16 & 11 & 0.43 \\
\hline Milk & 311 & 219 & 310 & 225 & 0.29 \\
\hline Cheese & 30 & 26 & 31 & 26 & 0.08 \\
\hline Fats & 30 & 21 & 30 & 20 & 0.27 \\
\hline Sweets, sugar & 12 & 17 & 13 & 16 & 0.09 \\
\hline \multicolumn{6}{|l|}{ Nutrient (intake/d)‡ } \\
\hline Energy (kJ) & 8120 & 2573 & 8299 & 2366 & $<0.0001$ \\
\hline Protein $(\mathrm{g})$ & 77 & 25 & 79 & 23 & $<0.0001$ \\
\hline Fat $(\mathrm{g})$ & 69 & 27 & 71 & 26 & $<0.0001$ \\
\hline Complex carbohydrates (g) & 208 & 63 & 213 & 61 & $<0.0001$ \\
\hline Simple carbohydrates (sugars) (g) & 34 & 26 & 33 & 23 & 0.95 \\
\hline Fibre $(g)$ & 23 & 8.2 & 25 & 7.9 & $<0.0001$ \\
\hline Cholesterol (mg) & 263 & 104 & 274 & 95 & $<0.0001$ \\
\hline Folate $(\mu \mathrm{g})$ & 293 & 112 & 362 & 151 & $<0.0001$ \\
\hline Vitamin $B_{12}(\mu \mathrm{g})$ & $6 \cdot 6$ & 3.8 & $7 \cdot 0$ & $3 \cdot 8$ & $<0.0001$ \\
\hline Vitamin $B_{6}(\mathrm{mg})$ & 1.4 & 0.5 & 1.9 & $1 \cdot 0$ & $<0.0001$ \\
\hline Riboflavin (mg) & 1.6 & 0.6 & $2 \cdot 2$ & $1 \cdot 1$ & $<0.0001$ \\
\hline Thiamine (mg) & 1.4 & 0.5 & $2 \cdot 0$ & 0.9 & $<0.0001$ \\
\hline Retinol equivalents $(\mu \mathrm{g})$ & 1884 & 1093 & 2513 & 1313 & $<0.0001$ \\
\hline$\beta$-Carotene $(\mu \mathrm{g})$ & 5219 & 3780 & 5909 & 3702 & $<0.0001$ \\
\hline Vitamin C (mg) & 149 & 92 & 185 & 95 & $<0.0001$ \\
\hline$\alpha$-Tocopherol (mg) & $10 \cdot 1$ & $5 \cdot 2$ & $15 \cdot 7$ & $8 \cdot 4$ & $<0.0001$ \\
\hline Vitamin D $(\mu \mathrm{g})$ & 8.5 & $7 \cdot 0$ & $13 \cdot 4$ & $9 \cdot 8$ & $<0.0001$ \\
\hline \multicolumn{6}{|l|}{ Plasma/serum concentration } \\
\hline Total homocysteine $(\mu \mathrm{mol} / \mathrm{l})$ & $11 \cdot 2$ & 4.0 & $10 \cdot 1$ & $3 \cdot 7$ & $<0.0001$ \\
\hline Folate $(\mathrm{nmol} / \mathrm{l})$ & $7 \cdot 7$ & 5.4 & $10 \cdot 6$ & $8 \cdot 3$ & $<0.0001$ \\
\hline Vitamin $\mathrm{B}_{12}(\mathrm{pmol} / \mathrm{l})$ & 381.0 & $235 \cdot 1$ & $400 \cdot 5$ & $242 \cdot 3$ & 0.02 \\
\hline Creatinine $(\mu \mathrm{mol} / \mathrm{l})$ & $90 \cdot 8$ & 14.3 & 88.5 & $12 \cdot 8$ & 0.03 \\
\hline
\end{tabular}

${ }^{*}$ Two-sided $P$ value for the difference between non-users and users of vitamin supplements. Logistic regression for the variables age, sex and smoking adjusted for age and/or sex, linear regression analyses for all other variables (categorized in quartiles) adjusted for age and sex. †Current smokers versus former and never smokers combined.

$\ddagger$ Includes intake from food and supplements.

Plasma total homocysteine according to food groups and food items intake

Table 4 shows mean differences in plasma tHcy concentration between quartiles of food group and food item intake with two different adjustment models. In comparison with the data in Table 2 adjusted only for age, sex and energy intake, further adjustment for smoking and coffee consumption made the association between tHcy and cakes stronger and statistically significant, whereas the association with fats became weaker and non-significant. For individual variables, significantly lower plasma tHcy was observed for higher intakes of citrus fruits, orange juice, cruciferous vegetables, spinach/green cabbage, non-processed meat and chicken, while a higher intake of processed meat was associated with higher tHcy concentrations. Further adjustments for BMI and serum creatinine only marginally altered the results, and are therefore not presented. 
Table 2. Mean difference in plasma total homocysteine concentration per increasing quartile of food group, nutrient intake, smoking and coffee consumption among non-users and users of vitamin supplements in the Hordaland Homocysteine Study

\begin{tabular}{|c|c|c|c|c|c|c|c|}
\hline & \multicolumn{3}{|c|}{ Non-users of vitamin supplements } & \multicolumn{3}{|c|}{ Users of vitamin supplements } & \multirow[b]{2}{*}{$P \neq$} \\
\hline & Mean* & $95 \% \mathrm{Cl}$ & $P \dagger$ & Mean* & $95 \% \mathrm{Cl}$ & $P \dagger$ & \\
\hline \multicolumn{8}{|l|}{ Food group } \\
\hline Bread & -0.09 & $-0.21,0.02$ & 0.12 & -0.14 & $-0.34,0.06$ & 0.18 & 0.31 \\
\hline Cereals & -0.18 & $-0.29,-0.06$ & 0.004 & -0.23 & $-0.43,-0.04$ & 0.02 & 0.21 \\
\hline Cakes, pies, cookies & 0.09 & $-0.02,0.20$ & 0.10 & 0.02 & $-0.17,0.21$ & 0.59 & 0.91 \\
\hline Fruits & -0.31 & $-0.41,-0.20$ & $<0.0001$ & -0.29 & $-0.48,-0.11$ & 0.002 & 0.71 \\
\hline Vegetables & -0.32 & $-0.42,-0.22$ & $<0.0001$ & -0.14 & $-0.33,0.04$ & 0.14 & 0.03 \\
\hline Potatoes & -0.03 & $-0.14,0.08$ & 0.61 & -0.06 & $-0.26,0.13$ & 0.52 & 0.68 \\
\hline Meat & -0.007 & $-0.13,0.12$ & 0.91 & 0.26 & $0.04,0.47$ & 0.02 & 0.002 \\
\hline Fish and sea food & -0.22 & $-0.33,-0.11$ & $<0.0001$ & -0.16 & $-0.35,0.03$ & 0.11 & 0.75 \\
\hline Eggs & -0.22 & $-0.32,-0.12$ & $<0.0001$ & -0.03 & $-0.21,0.15$ & 0.71 & 0.04 \\
\hline Milk and dairy food & -0.12 & $-0.23,-0.02$ & 0.02 & -0.01 & $-0.20,0.17$ & 0.88 & 0.21 \\
\hline Cheese & -0.04 & $-0.15,0.07$ & 0.46 & -0.17 & $-0.36,0.02$ & 0.09 & 0.60 \\
\hline Fats & 0.15 & $0.03,0.27$ & 0.01 & 0.42 & $0.21,0.63$ & $<0.0001$ & 0.003 \\
\hline Sweets, sugar & 0.21 & $0.11,0.32$ & $<0.0001$ & 0.38 & $0.20,0.57$ & $<0.0001$ & 0.02 \\
\hline \multicolumn{8}{|l|}{ Nutrient } \\
\hline Energy & $-0.13 \S$ & $-0.25,-0.02$ & 0.02 & $0.08 \S$ & $-0.11,0.29$ & 0.37 & $0.02 \S$ \\
\hline Protein & -0.46 & $-0.64,-0.28$ & $<0.0001$ & -0.36 & $-0.66,-0.05$ & 0.02 & 0.02 \\
\hline Fat & 0.49 & $0.31,0.67$ & $<0.0001$ & 0.61 & $0.29,0.94$ & 0.0002 & 0.009 \\
\hline Complex carbohydrates & -0.41 & $-0.59,-0.24$ & $<0.0001$ & -0.65 & $-0.94,-0.35$ & $<0.0001$ & 0.31 \\
\hline Simple carbohydrates (sugars) & 0.23 & $0.11,0.34$ & 0.0001 & 0.21 & $0.007,0.41$ & 0.04 & 0.33 \\
\hline Fibres & -0.38 & $-0.51,-0.25$ & $<0.0001$ & -0.45 & $-0.67,-0.23$ & $<0.0001$ & 0.41 \\
\hline Cholesterol & -0.10 & $-0.23,0.03$ & 0.14 & -0.007 & $-0.23,0.22$ & 0.95 & $0 \cdot 13$ \\
\hline Folate & -0.57 & $-0.71,-0.44$ & $<0.0001$ & -0.57 & $-0.77,-0.37$ & $<0.0001$ & 0.87 \\
\hline Vitamin $B_{12}$ & -0.27 & $-0.39,-0.15$ & $<0.0001$ & -0.17 & $-0.38,0.03$ & 0.10 & 0.38 \\
\hline Vitamin $B_{6}$ & -0.54 & $-0.68,-0.39$ & $<0.0001$ & -0.54 & $-0.74,-0.35$ & $<0.0001$ & 0.48 \\
\hline Riboflavin & -0.46 & $-0.60,-0.33$ & $<0.0001$ & -0.45 & $-0.64,-0.26$ & $<0.0001$ & $0 \cdot 16$ \\
\hline Thiamine & -0.64 & $-0.80,-0.47$ & $<0.0001$ & -0.47 & $-0.67,-0.28$ & $<0.0001$ & 0.26 \\
\hline Retinol equivalents & -0.33 & $-0.44,-0.22$ & $<0.0001$ & -0.22 & $-0.41,-0.04$ & 0.02 & 0.35 \\
\hline$\beta$-Carotene $(\mu \mathrm{g})$ & -0.29 & $-0.40,-0.19$ & $<0.0001$ & -0.27 & $-0.45,-0.09$ & 0.004 & 0.76 \\
\hline Vitamin C (mg) & -0.42 & $-0.53,-0.31$ & $<0.0001$ & -0.40 & $-0.59,-0.22$ & $<0.0001$ & 0.49 \\
\hline$\alpha$-Tocopherol (mg) & -0.27 & $-0.39,-0.15$ & $<0.0001$ & -0.29 & $-0.48,-0.11$ & 0.002 & 0.89 \\
\hline Vitamin D & -0.14 & $-0.25,-0.03$ & 0.01 & -0.18 & $-0.36,0.01$ & 0.06 & 0.90 \\
\hline \multicolumn{8}{|l|}{ Lifestyle factors } \\
\hline Smoking & $0.61 \S$ & $0.47,0.76$ & $<0.0001$ & $0.62 \S$ & $0.35,0.88$ & $<0.0001$ & $0.70 \S$ \\
\hline Coffee consumption & $0.33 \S$ & $0.22,0.44$ & $<0.0001$ & $0.30 \S$ & $0.11,0.49$ & $<0.0001$ & $0.73 \S$ \\
\hline
\end{tabular}

* Model I adjusted for age, sex and energy intake.

$\dagger$ Two-sided $P$ value for the effect of food group, nutrient, smoking and coffee consumption.

$¥$ Two-sided $P$ value for interaction of vitamin user group on the association between predictor variables and total homocysteine concentration, adjusted for age, sex and energy intake.

$\S$ Adjusted for age and sex.

Further adjustments for dietary B-vitamins generally resulted in weaker associations for all food variables, and the groups of vegetables, non-processed meat, processed meat, chicken, fish and milk were no longer significantly associated with tHcy (data not shown). The groups of fruits and orange juice were still inversely associated, while cakes and sweets were positively associated with tHcy concentration. After additional adjustment for plasma folate and vitamin $B_{12}$ the associations with fruits, orange juice and cakes became statistically non-significant, while sweets still related positively to tHcy. The inverse association with whole-grain bread and non-processed meat became stronger.

\section{Plasma total homocysteine according to nutrient intake}

Differences in plasma concentration of tHcy per increasing quartiles of nutrient intakes are shown in Table 5. After adjustment for smoking and coffee consumption most of the associations became weaker, while for protein, simple carbohydrates, cholesterol, vitamin $\mathrm{B}_{12}$ and vitamin $\mathrm{D}$ became stronger. The inverse association between cholesterol intake and plasma tHcy concentration became statistically significant. We observed inverse associations between dietary intake of thiamine, vitamins A (retinol equivalent and $\beta$-carotene), $\mathrm{E}$ ( $\alpha$-tocopherol), $\mathrm{D}$ and $\mathrm{C}$, and the plasma tHcy concentration. Adjustment for serum creatinine and BMI only marginally altered the results, and these data are therefore not presented.

After additional adjustment for dietary B-vitamins and plasma concentration of folate and vitamin $\mathrm{B}_{12}$, only complex carbohydrates (inversely), thiamine (inversely) and fat (positively) remained associated with plasma tHcy. Dietary folate and riboflavin (not adjusted for plasma concentrations) remained strongly associated with tHcy even after adjustment for the other dietary B-vitamins. This was not seen for vitamins $B_{12}$ and $B_{6}$ after similar adjustment. Vitamin $C$, retinol equivalent, $\beta$-carotene and simple carbohydrates remained significantly associated with tHcy after adjustment for dietary B-vitamins, but not after additional adjustment for plasma folate and vitamin $\mathrm{B}_{12}$. 
Table 3. Correlation between dietary intake and plasma B-vitamin concentration, other nutrients and food groups among non-users of vitamin supplements in the Hordaland Homocysteine Study*

\begin{tabular}{|c|c|c|c|c|c|c|}
\hline & \multicolumn{4}{|c|}{ Diet } & \multicolumn{2}{|c|}{ Plasma } \\
\hline & Folate & $\mathrm{B}_{12}$ & $\mathrm{~B}_{6}$ & Riboflavin & Folate & $\mathrm{B}_{12}$ \\
\hline \multicolumn{7}{|l|}{ Nutrient } \\
\hline Folate & & & & & $0 \cdot 19$ & 0.04 \\
\hline $\mathrm{B}_{12}$ & $0 \cdot 16$ & & & & $0.04 \dagger$ & 0.14 \\
\hline $\mathrm{B}_{6}$ & 0.58 & 0.42 & & & 0.18 & 0.08 \\
\hline Riboflavin & 0.37 & 0.40 & 0.42 & & 0.06 & 0.15 \\
\hline Thiamine & 0.63 & 0.20 & 0.57 & 0.56 & 0.08 & $0 \cdot 10$ \\
\hline Vitamin C & 0.76 & 0.08 & 0.59 & 0.24 & 0.20 & $0.02 \dagger$ \\
\hline Retinol equivalents & 0.39 & 0.28 & 0.27 & 0.22 & $0 \cdot 10$ & $0.04 \dagger$ \\
\hline$\beta$-Carotene & 0.51 & $0 \cdot 10$ & 0.41 & 0.14 & 0.13 & $0.03 \dagger$ \\
\hline Vitamin D & 0.07 & 0.38 & 0.22 & 0.09 & $0.04 \dagger$ & 0.05 \\
\hline$\alpha$-Tocopherol & 0.32 & 0.14 & 0.34 & $0 \cdot 16$ & $0 \cdot 10$ & $0.03 \dagger$ \\
\hline Protein & 0.24 & 0.63 & 0.48 & 0.48 & 0.04 & 0.15 \\
\hline Fat & -0.33 & 0.14 & -0.26 & $-0 \cdot 10$ & -0.08 & $-0.02 \dagger$ \\
\hline Complex carbohydrates & 0.46 & -0.17 & 0.24 & 0.13 & $0.04 \dagger$ & $0.02 \dagger$ \\
\hline Simple carbohydrates (sugars) & -0.21 & -0.19 & -0.25 & -0.21 & -0.08 & -0.05 \\
\hline Fibre & 0.66 & -0.06 & 0.47 & $0 \cdot 10$ & 0.12 & $0.005 \dagger$ \\
\hline Cholesterol & $0.02 \dagger$ & 0.51 & $0 \cdot 19$ & 0.23 & 0.05 & 0.05 \\
\hline \multicolumn{7}{|l|}{ Food group } \\
\hline Bread & 0.06 & -0.17 & -0.30 & -0.14 & -0.08 & $0.02 \dagger$ \\
\hline Cereals & 0.08 & $-0.01 \dagger$ & 0.14 & 0.08 & 0.04 & $-0.006 \dagger$ \\
\hline Cakes, pies, cookies & $-0.03 t$ & -0.06 & -0.08 & -0.06 & -0.05 & -0.06 \\
\hline Fruits & 0.38 & $-0.03 \dagger$ & 0.44 & $0.03 \dagger$ & 0.16 & $-0.001 \dagger$ \\
\hline Vegetables & 0.66 & 0.15 & 0.50 & 0.20 & $0 \cdot 17$ & $0.02 \dagger$ \\
\hline Potatoes & 0.12 & $0.02 \dagger$ & $0 \cdot 19$ & -0.07 & $-0.02 \dagger$ & $0.02 \dagger$ \\
\hline Meat & -0.08 & 0.21 & 0.17 & $-0.02 \dagger$ & $-0.003 \dagger$ & $-0.02 \dagger$ \\
\hline Fish & 0.17 & 0.66 & 0.49 & 0.11 & 0.06 & 0.09 \\
\hline Eggs & 0.07 & 0.18 & 0.07 & $0 \cdot 13$ & 0.05 & $0.02 \dagger$ \\
\hline Milk & $-0.04 \dagger$ & 0.21 & 0.06 & 0.60 & -0.08 & 0.14 \\
\hline Cheese & -0.06 & -0.04 & -0.15 & 0.16 & $0.007 \dagger$ & $0.03 \dagger$ \\
\hline Fats & -0.20 & $-0.02 \dagger$ & -0.24 & -0.22 & -0.07 & $-0.02 \dagger$ \\
\hline Sweets, sugar & -0.19 & -0.14 & -0.18 & -0.19 & $-0.03 \dagger$ & -0.05 \\
\hline Plasma total homocysteine & -0.15 & -0.07 & -0.14 & -0.12 & -0.37 & -0.22 \\
\hline
\end{tabular}

*Spearman's partial correlation coefficients adjusted for age, sex and energy intake. All coefficients are significant, except those marked $\dagger(P>0.01)$.

\section{Discussion}

In a large population-based sample of non-users of vitamin supplements, we observed that plasma tHcy is associated with several nutrients and foods. While the intake of complex carbohydrates and protein as well as several B-vitamins were associated with lower tHcy concentrations, the intake of fat and sugar were associated with higher plasma tHcy. Consumption of vegetables, fruits, bread, cereals, fish, non-processed meat, chicken, eggs and milk was associated with lower tHcy concentrations, while intake of sweets, cakes and processed meat was related to higher tHcy concentrations. The present results confirm the importance of lifestyle factors as a major determinant of tHcy.

\section{Limitations and strengths}

The current study was conducted in a large population-based sample, using a validated 169-item quantitative FFQ (Andersen et al. 1995, 1999). This allowed the investigation of dietary predictors of tHcy in multivariate models. A limitation relates to the collection of dietary data using a FFQ, which has inherent potential problems related to inaccuracy and potential misclassification in the estimation of nutrient intake (Willett \& Lenart, 1998; Flood et al. 2004): reported associations between dietary non-B-vitamin nutrients and
tHcy concentration could be due to confounding effects of dietary B-vitamin intake (Shimakawa et al. 1997; Brude et al. 1999). We therefore repeated the analyses using a model that included adjustment for dietary and plasma folate and vitamin $\mathrm{B}_{12}$ when examining these associations.

\section{Users and non-users of vitamin supplements}

In accordance with previous reports (Tucker et al. 1996; Nygard et al. 1998; Malinow et al. 1999; Koehler et al. 2001), we observed that users and non-users of vitamin supplements differed with respect to lifestyle, dietary habits and plasma vitamin concentrations. Users were more likely to be non-smokers, consume less coffee and generally have a more healthy diet compared to non-users, and to have lower concentrations of plasma tHcy, but higher concentration of folate and vitamin $\mathrm{B}_{12}$ as compared to non-users. There was an effect modification of vitamin supplement use on the association between various nutrients, food groups and plasma tHcy. We are not aware that this has previously been reported.

\section{B-vitamins}

The present findings confirm previous studies reporting inverse associations between dietary intake of folate, vitamin 
Table 4. Mean difference in plasma total homocysteine concentration per increasing quartiles of food intake among non-users of vitamin supplements in the Hordaland Homocysteine Study

\begin{tabular}{|c|c|c|c|c|c|c|}
\hline Food group/food item & Mean* & $95 \% \mathrm{Cl}$ & $P \dagger$ & Mean $\ddagger$ & $95 \% \mathrm{Cl}$ & $P \dagger$ \\
\hline Bread, group & -0.09 & $-0.20,0.03$ & 0.15 & -0.17 & $-0.28,-0.06$ & 0.003 \\
\hline Refined (white) bread & 0.14 & $-0.01,0.30$ & 0.07 & 0.04 & $-0.10,0.19$ & 0.56 \\
\hline Whole-grain bread & $-0 \cdot 10$ & $-0.21,0.004$ & 0.06 & -0.14 & $-0.24,-0.04$ & 0.007 \\
\hline Cereals, group & -0.13 & $-0.25,-0.01$ & 0.03 & -0.08 & $-0.19,0.03$ & 0.14 \\
\hline Cakes, pies, cookies, group & 0.14 & $0.03,0.24$ & 0.01 & 0.03 & $-0.07,0.13$ & 0.56 \\
\hline Fruits, group & -0.24 & $-0.34,-0.14$ & $<0.0001$ & -0.007 & $-0.11,0.10$ & 0.90 \\
\hline Citrus fruits & -0.25 & $-0.34,-0.16$ & $<0.0001$ & -0.09 & $-0.17,-0.0005$ & 0.05 \\
\hline Apples, pears & -0.15 & $-0.25,-0.05$ & 0.003 & -0.04 & $-0.13,0.05$ & 0.42 \\
\hline Orange juice & -0.20 & $-0.29,-0.10$ & $<0.0001$ & -0.02 & $-0.11,0.07$ & 0.69 \\
\hline Vegetables, group & -0.32 & $-0.42,-0.22$ & $<0.0001$ & 0.002 & $-0.12,0.12$ & 0.97 \\
\hline Carrot & -0.29 & $-0.40,-0.19$ & $<0.0001$ & -0.16 & $-0.26,-0.06$ & 0.001 \\
\hline Kohlrabi, turnips & -0.15 & $-0.25,-0.06$ & 0.002 & -0.02 & $-0.11,0.07$ & 0.66 \\
\hline Cabbage & -0.09 & $-0.19,-0.002$ & 0.05 & -0.04 & $-0.13,0.05$ & 0.36 \\
\hline Cauliflower, broccoli, Brussels sprouts & -0.17 & $-0.27,-0.07$ & 0.0009 & 0.08 & $-0.02,0.18$ & 0.13 \\
\hline Onions & -0.22 & $-0.32,-0.13$ & $<0.0001$ & -0.09 & $-0.18,-0.004$ & 0.04 \\
\hline Lettuces & -0.16 & $-0.26,-0.05$ & 0.003 & -0.002 & $-0 \cdot 10,0 \cdot 10$ & 0.96 \\
\hline Cucumber & -0.14 & $-0.24,-0.04$ & 0.006 & 0.005 & $-0.09,0.10$ & 0.92 \\
\hline Tomato & -0.20 & $-0.30,-0.10$ & 0.0002 & 0.02 & $-0.08,0.12$ & 0.74 \\
\hline Pepper & -0.21 & $-0.31,-0.10$ & 0.0001 & -0.02 & $-0.12,0.08$ & 0.71 \\
\hline Green cabbage, spinach & -0.21 & $-0.31,-0.11$ & $<0.0001$ & -0.03 & $-0.13,0.07$ & 0.56 \\
\hline Mushrooms & -0.14 & $-0.24,-0.04$ & 0.007 & 0.05 & $-0.07,0.11$ & 0.69 \\
\hline Potatoes, group & -0.05 & $-0.16,0.06$ & 0.41 & -0.05 & $-0.15,0.05$ & 0.33 \\
\hline Meat, group & -0.06 & $-0.19,0.06$ & 0.33 & -0.08 & $-0.20,0.04$ & 0.17 \\
\hline Non-processed meat & -0.13 & $-0.23,-0.02$ & 0.02 & -0.11 & $-0.21,-0.004$ & 0.04 \\
\hline Processed meat & 0.12 & $0.002,0.23$ & 0.05 & 0.02 & $-0.09,0.12$ & 0.75 \\
\hline Chicken & -0.15 & $-0.25,-0.05$ & 0.003 & -0.08 & $-0.17,0.02$ & $0 \cdot 10$ \\
\hline Fish and seafood, group & -0.22 & $-0.33,-0.11$ & $<0.0001$ & -0.07 & $-0.20,0.06$ & 0.28 \\
\hline Egg, group & -0.26 & $-0.36,-0.17$ & $<0.0001$ & -0.18 & $-0.27,-0.09$ & $<0.0001$ \\
\hline Milk and dairy food, group & -0.11 & $-0.21,-0.01$ & 0.03 & -0.03 & $-0.14,0.09$ & 0.63 \\
\hline Cheese, group & -0.01 & $-0.12,0.09$ & 0.83 & 0.03 & $-0.07,0.13$ & 0.56 \\
\hline Fats, group & 0.08 & $-0.04,0.20$ & 0.18 & -0.02 & $-0.13,0.09$ & 0.68 \\
\hline Sweets, sugar, group & 0.21 & $0.11,0.32$ & $<0.0001$ & 0.11 & $0.01,0.21$ & 0.02 \\
\hline
\end{tabular}

${ }^{*}$ Model II adjusted for age, sex, energy intake, smoking and coffee consumption.

$\dagger$ Two-sided $P$ value for the effect of food group and food item.

$\ddagger$ Model III adjusted for age, sex, smoking, coffee consumption, intake of dietary energy, folate, vitamin $\mathrm{B}_{12}$, vitamin $\mathrm{B}_{6}$ and riboflavin, and plasma folate and vitamin $\mathrm{B}_{12}$.

Table 5. Mean difference in plasma total homocysteine concentration per increasing quartiles of nutrient intake among nonusers of vitamin supplements in the Hordaland Homocysteine Study

\begin{tabular}{|c|c|c|c|c|c|c|}
\hline Nutrient & Mean* & $95 \% \mathrm{Cl}$ & P† & Mean‡ & $95 \% \mathrm{Cl}$ & $P \dagger$ \\
\hline Energy & $-0.15 \S$ & $-0.26,-0.03$ & 0.01 & $0.16 \S$ & $0.001,0.32$ & 0.08 \\
\hline Protein & -0.47 & $-0.65,-0.30$ & $<0.0001$ & -0.18 & $-0.39,0.03$ & 0.09 \\
\hline Fat & 0.38 & $0.20,0.56$ & $<0.0001$ & 0.27 & $0.10,0.44$ & 0.002 \\
\hline Complex carbohydrates & -0.35 & $-0.52,-0.17$ & 0.0001 & -0.20 & $-0.38,-0.02$ & 0.03 \\
\hline Simple carbohydrates (sugars) & 0.25 & $0.13,0.36$ & $<0.0001$ & 0.06 & $-0.04,0.17$ & 0.25 \\
\hline Fibres & -0.31 & $-0.44,-0.18$ & $<0.0001$ & -0.06 & $-0.21,0.09$ & 0.45 \\
\hline Cholesterol & -0.16 & $-0.29,-0.03$ & 0.01 & -0.03 & $-0.16,0.10$ & 0.66 \\
\hline Folate & -0.53 & $-0.67,-0.39$ & $<0.0001$ & $-0.36 \|$ & $-0.53,-0.20$ & $<0.0001$ \\
\hline Vitamin $B_{12}$ & -0.29 & $-0.41,-0.18$ & $<0.0001$ & $-0.13 \|$ & $-0.26,0.007$ & 0.06 \\
\hline Vitamin $\mathrm{B}_{6}$ & -0.49 & $-0.63,-0.34$ & $<0.0001$ & $-0.15 \|$ & $-0.33,0.04$ & 0.11 \\
\hline Riboflavin & -0.42 & $-0.55,-0.28$ & $<0.0001$ & $-0.17 \|$ & $-0.32,-0.006$ & 0.04 \\
\hline Thiamine & -0.59 & $-0.75,-0.43$ & $<0.0001$ & -0.30 & $-0.50,-0.09$ & 0.004 \\
\hline Retinol equivalents & -0.33 & $-0.44,-0.22$ & $<0.0001$ & $-0 \cdot 10$ & $-0.21,0.01$ & 0.07 \\
\hline$\beta$-Carotene & -0.29 & $-0.39,-0.19$ & $<0.0001$ & -0.06 & $-0.17,0.04$ & 0.25 \\
\hline$\alpha$-Tocopherol & -0.24 & $-0.36,-0.12$ & 0.0001 & -0.01 & $-0.13,0.11$ & 0.87 \\
\hline Vitamin D & -0.15 & $-0.26,-0.04$ & 0.008 & -0.02 & $-0.13,0.09$ & $0 \cdot 70$ \\
\hline Vitamin C & -0.38 & $-0.49,-0.27$ & $<0.0001$ & -0.003 & $-0.14,0.14$ & 0.97 \\
\hline
\end{tabular}

${ }^{*}$ Model II adjusted for age, sex, energy intake, smoking and coffee consumption.

$\dagger$ Two-sided $P$ value for the effect of nutrient.

$\ddagger$ Model III adjusted for age, sex, smoking, coffee consumption, intake of energy, dietary folate, vitamin $B_{12}$, vitamin $B_{6}$ and riboflavin, and plasma folate and vitamin $\mathrm{B}_{12}$

$\S$ Not adjusted for energy intake.

\| Not adjusted for plasma folate and vitamin $\mathrm{B}_{12}$ 
$\mathrm{B}_{12}$, vitamin $\mathrm{B}_{6}$ and riboflavin, and plasma concentration of tHcy (de Bree et al. 2001, 2002; Jacques et al. 2001; Verhoef $\&$ de Groot, 2005). However, only folate and riboflavin remained significantly related to tHcy after adjusting for other dietary B-vitamins. This does not negate an effect of vitamins $\mathrm{B}_{12}$ and $\mathrm{B}_{6}$ on plasma tHcy concentration, because intake of these four B-vitamins is to a significant extent strongly intercorrelated (Shimakawa et al. 1997) due to similar dietary sources. Second, because these B-vitamins are all involved in homocysteine metabolism, they have a complementary lowering effect on tHcy concentration (Bostom et al. 2002; Huerta et al. 2004). Adjustment of an individual B-vitamin for other vitamins in a related metabolic cycle could significantly reduce or mask their individual effect. Among the four B-vitamins, our analysis confirmed that the individual effect of folate was stronger than the effects of riboflavin, vitamin $\mathrm{B}_{12}$ and vitamin $\mathrm{B}_{6}$ (de Bree et al. 2001; Jacques et al. 2001).

\section{Other nutrients}

We found significant inverse associations between plasma tHcy and dietary intake of vitamins C, E and D, retinol equivalent and $\beta$-carotene, in accordance with previous reports (Brude et al. 1999; Vollset et al. 2001). The intake of these vitamins is correlated with dietary B-vitamins, indicating overlapping dietary sources. Nevertheless, after adjustment for dietary B-vitamins, retinol equivalents, $\beta$-carotene and vitamin $C$ remained significantly inversely related to plasma tHcy concentration. However, after further adjustments for plasma folate and vitamin $B_{12}$, these associations were no longer significant.

We observed an inverse association between protein intake and plasma tHcy (Stolzenberg-Solomon et al. 1999; Jacques et al. 2001). However, there are strong positive correlations between dietary intake of protein and riboflavin, vitamin $\mathrm{B}_{12}$ and vitamin $\mathrm{B}_{6}$, and after adjusting for dietary $\mathrm{B}$-vitamins the association between protein and tHcy became non-significant. As for protein, the association between fibre intake and plasma tHcy was no longer significant after adjustment for the intake of B-vitamins.

The intake of complex carbohydrates was inversely related to tHcy concentration, an association that remained significant after adjusting for dietary and plasma B-vitamins. Complex carbohydrates is a macro-nutrient that is not involved in methionine-homocysteine metabolism, thus the inverse association with tHcy could be due to residual confounding from common dietary sources with B-vitamins. Another possible explanation is related to the construction and limitations of the FFQ. For example, choline and betaine are not included in the Norwegian food composition tables, and we could therefore not examine whether the associations could be due to the dietary content of these factors. Some studies (Sakamoto et al. 2002; Zeisel et al. 2003) as well as the USDA National Nutrient Database for Standard Reference (US Department of Agriculture, 2005) report a high content of these quaternary ammonium compounds in some plant food, and negative associations between intake and plasma concentrations of choline, betaine and plasma tHcy have been reported in previous studies (Olthof et al. 2005; Ueland et al. 2005; Cho et al. 2006).

\section{Food groups and food items}

In line with previous studies (Vollset et al. 2001; Ganji \& Kafai, 2004), we found inverse associations between plasma tHcy and dietary intake of citrus fruit, orange juice, cruciferous vegetables, spinach/green cabbage and peppers. Furthermore, we observed, as have others, that plasma tHcy is inversely associated with milk (Shimakawa et al. 1997; Ganji \& Kafai, 2004) and fish (Brude et al. 1999). We also found inverse relations with apples, carrots, onions, lettuce, cucumbers, tomatoes, mushrooms and eggs.

The overall food group of meat was not significantly related to tHcy. However, further examination revealed that non-processed meat and chicken were inversely, while processed meat was positively associated with tHcy. Non-processed meat is a source of protein, vitamin $\mathrm{B}_{12}$, vitamin $\mathrm{B}_{6}$, riboflavin, choline and betaine which all are negatively associated with plasma tHcy (Holm et al. 2005; Cho et al. 2006). Processed meat contains less protein and B-vitamins but more fat than non-processed meat. The nutrient fat is positively related to tHcy, and this may partly explain the positive association with processed meat (Appel et al. 2000). Associations between tHcy and different types of fat will be examined in more detail in a forthcoming paper from our group (P Berstad et al., unpublished results).

The intake of sweets and cakes, high in fat and sugar, was associated with high tHcy concentrations, consistent with the present finding that the intake of simple carbohydrates (sugar) was negatively associated with dietary folate, vitamin $\mathrm{B}_{12}$, vitamin $\mathrm{B}_{6}$ and riboflavin.

After additional adjustment for dietary B-vitamins and for plasma folate and vitamin $B_{12}$, whole-grain bread, eggs, sweets, citrus fruits, carrots, onions and non-processed meat remained significantly associated with plasma tHcy concentration. This could be due to residual confounding, or that these food groups or items contain choline, betaine or methionine (Jacques et al. 2001; Verhoef \& de Groot, 2005; Cho et al. 2006). A high content of these compounds has been reported in eggs, whole-wheat bread, meat and liver, and a lower content in fruits and vegetables (Zeisel et al. 2003; US Department of Agriculture, 2005). The relationship between tHcy concentration and dietary choline, betaine and methionine should be further examined.

Because people do not eat individual nutrients and food items in isolation, it is important to examine the effect of the total diet on plasma tHcy concentration. Although in the present study we did not evaluate the effect of the total diet, the present results are in general agreement with studies that have examined associations between dietary patterns and tHcy (Fung et al. 2001; Gao et al. 2003; Lasheras et al. 2003; Weikert et al. 2005), namely inverse associations between tHcy and diets rich in fruits, vegetables, fish, meat, milk, whole-grain bread and mushrooms (Gao et al. 2003; Lasheras et al. 2003; Weikert et al. 2005). Dietary patterns high in refined cereals (Gao et al. 2003), fat (Appel et al. 2000; Weikert et al. 2005) and sugar have been associated with higher tHcy levels (Fung et al. 2001).

\section{Implications and conclusion}

The present findings suggest that in a Norwegian adult and elderly population not taking vitamin supplements, plasma 
tHcy concentration may be lowered with a diet rich in complex carbohydrates, protein and B-vitamins. Such a diet includes vegetables, fruits, whole-grain bread and cereals, as well as fish, non-processed meat, chicken and eggs. A high consumption of fat and sugar-rich foods such as sweets, cakes and processed meat may increase tHcy concentration. In conclusion, a diet high in B-vitamins and low in fat and sugar is associated with low plasma tHcy concentration in a population not taking vitamin supplements.

\section{Acknowledgements}

This work was supported by a research grant from the Norwegian Research Council, Western Norway Regional Health Authority (project no. 911177), the Foundation to Promote Research into Functional Vitamin B12 Deficiency and Johan Throne Holst Foundation for Nutrition Research. We thank Kari Solvoll for construction of the FFQ, nutrient and food intake assessment. None of the authors have any personal or financial conflicts in this work.

\section{References}

Andersen LF, Nes M, Lillegaard IT, Sandstad B, Bjorneboe GE \& Drevon CA (1995) Evaluation of a quantitative food frequency questionnaire used in a group of Norwegian adolescents. Eur $J$ Clin Nutr 49, 543-554.

Andersen LF, Solvoll K, Johansson LR, Salminen I, Aro A \& Drevon CA (1999) Evaluation of a food frequency questionnaire with weighed records, fatty acids, and alpha-tocopherol in adipose tissue and serum. Am J Epidemiol 150, 75-87.

Appel LJ, Miller ER 3rd, Jee SH, Stolzenberg-Solomon R, Lin PH, Erlinger T, Nadeau MR \& Selhub J (2000) Effect of dietary patterns on serum homocysteine: results of a randomized, controlled feeding study. Circulation 102, 852-857.

Bonaa KH, Njolstad I, Ueland PM, Schirmer H, Tverdal A, Steigen T, Wang H, Nordrehaug JE, Arnesen E \& Rasmussen K (2006) Homocysteine lowering and cardiovascular events after acute myocardial infarction. $N$ Engl J Med 354, 1578-1588.

Bostom AG, Jacques PF, Liaugaudas G, Rogers G, Rosenberg IH \& Selhub J (2002) Total homocysteine lowering treatment among coronary artery disease patients in the era of folic acid-fortified cereal grain flour. Arterioscler Thromb Vasc Biol 22, 488-491.

Brude IR, Finstad HS, Seljeflot I, Drevon CA, Solvoll K, Sandstad B, Hjermann I, Arnesen H \& Nenseter MS (1999) Plasma homocysteine concentration related to diet, endothelial function and mononuclear cell gene expression among male hyperlipidaemic smokers. Eur J Clin Invest 29, 100-108.

Castro R, Rivera I, Blom HJ, Jakobs C \& de Almeida IT (2006) Homocysteine metabolism, hyperhomocysteinaemia and vascular disease: an overview. J Inherit Metab Dis 29, 3-20.

Cho E, Zeisel SH, Jacques P, Selhub J, Dougherty L, Colditz GA \& Willett WC (2006) Dietary choline and betaine assessed by foodfrequency questionnaire in relation to plasma total homocysteine concentration in the Framingham Offspring Study. Am J Clin Nutr 83, 905-911.

Clarke R (2005) Homocysteine-lowering trials for prevention of heart disease and stroke. Semin Vasc Med 5, 215-222.

Daly S, Cotter A, Molloy AE \& Scott J (2005) Homocysteine and folic acid: implications for pregnancy. Semin Vasc Med 5, 190-200.

de Bree A, Verschuren WM, Blom HJ \& Kromhout D (2001) Association between $\mathrm{B}$ vitamin intake and plasma homocysteine concentration in the general Dutch population aged 20-65y. Am J Clin Nutr 73, 1027-1033.

de Bree A, Verschuren WM, Kromhout D, Kluijtmans LA \& Blom HJ (2002) Homocysteine determinants and the evidence to what extent homocysteine determines the risk of coronary heart disease. Pharmacol Rev 54, 599-618.

Finkelstein JD (1990) Methionine metabolism in mammals. J Nutr Biochem 1, 228-237.

Fiskerstrand T, Refsum H, Kvalheim G \& Ueland PM (1993) Homocysteine and other thiols in plasma and urine: automated determination and sample stability. Clin Chem 39, 263-271.

Flood VM, Smith WT, Webb KL \& Mitchell P (2004) Issues in assessing the validity of nutrient data obtained from a food-frequency questionnaire: folate and vitamin B12 examples. Public Health Nutr 7, 751-756.

Fung TT, Rimm EB, Spiegelman D, Rifai N, Tofler GH, Willett WC \& Hu FB (2001) Association between dietary patterns and plasma biomarkers of obesity and cardiovascular disease risk. Am J Clin Nutr 73, 61-67.

Ganji V \& Kafai MR (2004) Frequent consumption of milk, yogurt, cold breakfast cereals, peppers, and cruciferous vegetables and intakes of dietary folate and riboflavin but not vitamins B-12 and B-6 are inversely associated with serum total homocysteine concentrations in the US population. Am $J$ Clin Nutr 80, $1500-1507$.

Ganji V \& Kafai MR (2006) Trends in serum folate, RBC folate, and circulating total homocysteine concentrations in the United States: analysis of data from National Health and Nutrition Examination Surveys, 1988-1994, 1999-2000, and 2001-2002. J Nutr 136, $153-158$

Gao X, Yao M, McCrory AM, Ma G, Li Y, Roberts SB \& Tucker KL (2003) Dietary pattern is associated with homocysteine and B vitamin status in an urban Chinese population. J Nutr 133, 3636-3642.

Gjesdal CG, Vollset SE, Ueland PM, Refsum H, Drevon CA, Gjessing HK \& Tell GS (2006) Plasma total homocysteine level and bone mineral density: the Hordaland Homocysteine Study. Arch Intern Med 166, 88-94.

Holm PI, Ueland PM, Vollset SE, Midttun O, Blom HJ, Keijzer MB $\&$ den Heijer M (2005) Betaine and folate status as cooperative determinants of plasma homocysteine in humans. Arterioscler Thromb Vasc Biol 25, 379-385.

Huerta JM, Gonzalez S, Vigil E, Prada M, San Martin J, Fernandez S, Patterson AM \& Lasheras C (2004) Folate and cobalamin synergistically decrease the risk of high plasma homocysteine in a nonsupplemented elderly institutionalized population. Clin Biochem 37, 904-910.

Jacques PF, Bostom AG, Wilson PW, Rich S, Rosenberg IH \& Selhub J (2001) Determinants of plasma total homocysteine concentration in the Framingham Offspring cohort. Am J Clin Nutr 73, 613-621.

Jacques PF, Selhub J, Bostom AG, Wilson PW \& Rosenberg IH (1999) The effect of folic acid fortification on plasma folate and total homocysteine concentrations. $N$ Engl J Med 340, $1449-1454$.

Kelleher BP \& Broin SD (1991) Microbiological assay for vitamin B12 performed in 96-well microtitre plates. J Clin Pathol 44, $592-595$.

Koehler KM, Baumgartner RN, Garry PJ, Allen RH, Stabler SP \& Rimm EB (2001) Association of folate intake and serum homocysteine in elderly persons according to vitamin supplementation and alcohol use. Am J Clin Nutr 73, 628-637.

Lasheras C, Huerta JM, Gonzales S, Prada M, Braga S, Fernandez S \& Patterson AM (2003) Diet score is associated with plasma homocysteine in a healthy institutionalised elderly population. Nutr Metab Cardiovasc Dis 13, 384-390.

Loscalzo J (2006) Homocysteine trials - clear outcomes for complex reasons. $N$ Engl J Med 354, 1629-1632. 
Malinow MR, Bostom AG \& Krauss RM (1999) Homocyst(e)ine, diet, and cardiovascular diseases: a statement for healthcare professionals from the Nutrition Committee, American Heart Association. Circulation 99, 178-182.

Molloy AM \& Scott JM (1997) Microbiological assay for serum, plasma, and red cell folate using cryopreserved, microtiter plate method. Methods Enzymol 281, 43-53.

Morris MS (2003) Homocysteine and Alzheimer's disease. Lancet Neurol 2, 425-428.

Nygard O, Refsum H, Ueland PM \& Vollset SE (1998) Major lifestyle determinants of plasma total homocysteine distribution: the Hordaland Homocysteine Study. Am J Clin Nutr 67, 263-270.

Olthof MR, Brink EJ, Katan MB \& Verhoef P (2005) Choline supplemented as phosphatidylcholine decreases fasting and postmethionine-loading plasma homocysteine concentrations in healthy men. Am J Clin Nutr 82, 111-117.

Ortega RM, Requejo AM, Lopez-Sobaler AM, Navia B, Mena MC, Basabe B \& Andres P (2004) Smoking and passive smoking as conditioners of folate status in young women. J Am Coll Nutr 23, 365-371.

Perna AF, Ingrosso D, Satta E, Lombardi C, Acanfora F \& De Santo NG (2004) Homocysteine metabolism in renal failure. Curr Opin Clin Nutr Metab Care 7, 53-57.

Pfeiffer CM, Caudill SP, Gunter EW, Osterloh J \& Sampson EJ (2005) Biochemical indicators of B vitamin status in the US population after folic acid fortification: results from the National Health and Nutrition Examination Survey 1999-2000. Am J Clin Nutr 82, 442-450.

Ranheim T \& Halvorsen B (2005) Coffee consumption and human health - beneficial or detrimental? Mechanisms for effects of coffee consumption on different risk factors for cardiovascular disease and type 2 diabetes mellitus. Mol Nutr Food Res 49, 274-284.

Rimestad A, Borgejordet A, Vesterhus K, Sygnestveit K, Løken E, Trygg K, Pollestad M, Lund-Larsen K, Omholt-Jensen G \& Nordbotten A (2001) Den store matvaretabellen. (The Norwegian Food Composition Table.). Oslo: National Nutritional Council, Gyldendal undervisning.

Sakamoto A, Nishimura Y, Ono H \& Sakura N (2002) Betaine and homocysteine concentrations in foods. Pediatr Int 44, 409-413.

Scholl TO \& Johnson WG (2000) Folic acid: influence on the outcome of pregnancy. Am J Clin Nutr 71, 1295S-1303S.
Shimakawa T, Nieto FJ, Malinow MR, Chambless LE, Schreiner PJ \& Szklo M (1997) Vitamin intake: a possible determinant of plasma homocyst(e)ine among middle-aged adults. Ann Epidemiol 7, 285-293.

Stolzenberg-Solomon RZ, Miller ER 3rd, Maguire MG, Selhub J \& Appel LJ (1999) Association of dietary protein intake and coffee consumption with serum homocysteine concentrations in an older population. Am J Clin Nutr 69, 467-475.

Tucker KL, Selhub J, Wilson PW \& Rosenberg IH (1996) Dietary intake pattern relates to plasma folate and homocysteine concentrations in the Framingham Heart Study. J Nutr 126, 3025-3031.

Ueland PM, Holm PI \& Hustad S (2005) Betaine: a key modulator of one-carbon metabolism and homocysteine status. Clin Chem Lab Med 43, 1069-1075.

US Department of Agriculture (2005) USDA National Nutrient Database for Standard Reference: Nutrient Data Laboratory, release 18, http://www.nal.usda.gov/fnic/foodcomp. Beltsville, MD: US Department of Agriculture.

Verhoef P \& de Groot LC (2005) Dietary determinants of plasma homocysteine concentrations. Semin Vasc Med 5, 110-123.

Vollset SE, Refsum H, Nygård O \& Ueland PM (2001) Lifestyle factors associated with hyperhomocysteinemia. In Homocysteine in Health and Disease, pp. 341-355 [R Carmel and DW Jacobsen, editors]. Cambridge: Cambrige University Press.

Wald DS, Law M \& Morris JK (2002) Homocysteine and cardiovascular disease: evidence on causality from a meta-analysis. $\mathrm{Br} \mathrm{Med}$ J 325, 1202.

Weikert C, Hoffmann K, Dierkes J, Zyriax BC, Klipstein-Grobusch K, Schulze MB, Jung R, Windler E \& Boeing H (2005) A homocysteine metabolism-related dietary pattern and the risk of coronary heart disease in two independent German study populations. J Nutr 135, 1981-1988.

Willett W \& Lenart E (1998) Reproducibility and validity of food-frequency questionnaires. In Nutritional Epidemiology, 2nd ed. pp. 101-147 [W Willett, editor]. Oxford: Oxford University Press.

Zeisel SH, Mar MH, Howe JC \& Holden JM (2003) Concentrations of choline-containing compounds and betaine in common foods. J Nutr 133, 1302-1307. 